\title{
Congenital hypothyroidism due to ectopic sublingual thyroid gland in Prader-Willi Syndrome: a case report
}

\author{
Sarah Bocchini ${ }^{1}$, Danilo Fintini ${ }^{2}$, Graziano Grugni ${ }^{3}$, Arianna Boiani ${ }^{1}$, Alessio Convertino ${ }^{1}$ and Antonino Crinò ${ }^{{ }^{*}}$ (D)
}

\begin{abstract}
Background: Thyroid gland disorders are variably associated with Prader-Willi syndrome (PWS).

Many of the clinical features in newborns with PWS are similar to those found in congenital hypothyroidism (CH).

Case presentation: We report a case of a girl with $\mathrm{CH}$ and PWS. At the age of 9 months $\mathrm{CH}$ caused by an ectopic sublingual thyroid was diagnosed, and hormone replacement therapy was started. In spite of this treatment a decrease in growth velocity, weight excess and delayed development were observed. At the age of 9 years PWS was suspected on the basis of phenotype and genetic tests confirmed a maternal uniparental disomy of chromosome 15. This is the second reported case of hypothyroidism due to an ectopic sublingual thyroid gland in PWS suggesting that, although rare, an association between CH and PWS may exist. In our case diagnosis of PWS was delayed because mental retardation, hypotonia, obesity and short stature were initially attributed to hypothyroidism.

Conclusions: In this context PWS should be considered in obese children with $\mathrm{CH}$ who do not improve adequately with I-thyroxine therapy. Also, thyroid function in all PWS children should be assessed regularly in order to avoid delayed diagnosis of hypothyroidism.
\end{abstract}

Keywords: Prader-Willi syndrome, Hypothyroidism, Obesity, Hypotonia, Obesity

\section{Estabilished facts}

- Thyroid axis dysfunction does not seem to be a very common feature during infancy in PWS.

- Many of the clinical features in newborns with PWS are similar to those found in congenital hypothyroidism.

\section{Novel insights}

- The presence of congenital hypothyroidism may delay the diagnosis in subjects affected by PWS.

- PWS should always be considered in patients with congenital hypothyroidism and failure to thrive, and who do not improve adequately with the thyroid hormone replacement therapy.

\footnotetext{
* Correspondence: antonino.crino@opbg.net

'Autoimmune Endocrine Diseases Unit, Bambino Gesù Children's Hospital,

Research Institute, Palidoro, Rome, Italy

Full list of author information is available at the end of the article
}

\section{Background}

Prader-Willi syndrome (PWS) is a rare genetic disorder caused by the absent expression of the paternal active genes in the PWS critical region of chromosome 15. Three main genetic mechanisms are responsible for PWS: paternal chromosome 15q11-q13 deletion (70\%), maternal uniparental disomy for chromosome 15 (UPD15) (20-30\%), and imprinting center defects (ID) (1-3\%) [1]. The birth prevalence of PWS with molecular diagnosis is estimated to be about 1:15,000 [2], representing the most common syndromal cause of lifethreatening obesity [3]. The clinical phenotype of PWS patients is mainly characterized by neonatal hypotonia, hyperphagia leading to severe obesity in early childhood (if uncontrolled), short stature, multiple endocrine defects, small hands and feet, scoliosis, sleep disorders, developmental delay with cognitive impairment, behavioural and learning problems and characteristic facial appearance [3, 4].

A complex hypothalamic dysfunction is believed to be responsible for this multifaceted phenotype, including a 
dysregulation of GH-IGF-I axis, hypogonadism, adrenal insufficiency, and altered pituitary-thyroid axis $[5,6]$.

Published data on disorders of thyroid function and morphology in PWS are very limited. Thyroid axis dysfunction is not very common during infancy in PWS, while hypothyroidism variably affects a significant number of older children and adults with PWS. Untreated thyroid axis impairment causes the most damaging consequences during the first months of infancy, when thyroid hormones exert a critical action on neurological development. In this context, a recent study revealed a normal neonatal thyroid screening test in 23 newborns with PWS [7]. On the other hand, an investigation during the first 2 months of postnatal life found low free thyroxine (FT4) levels, in the presence of normal thyroid-stimulating hormone (TSH) in one third of subjects with PWS [8]. Moreover, other authors have demonstrated that a thyrotropinreleasing hormone (TRH)-TSH thyroid axis dysfunction is a common feature in infants with PWS [9]. It is of note that hypothyroidism, similarly to PWS, is characterized by hypotonia and delayed psychomotor development when present early in life, and is associated with weight gain, impaired growth and learning problems when it is present during childhood [10, 11].

In addition to the disruption of the thyroid function at the central level [12], other causes of neonatal thyroid abnormalities have been reported in PWS subjects, including the presence of fetal goiter in a newborn with UPD15 [13] and ectopic location of the thyroid gland in 1-yr-old female with $\mathrm{CH}$ [14].

We report the second case of sublingual thyroid gland in a female patient with PWS, where the diagnosis of congenital hypothyroidism was missed on newborn screening.

\section{Case presentation}

The patient is a 28.9-year-old woman, born after a fullterm pregnancy from unrelated healthy parents. Maternal age was 44 years and paternal age was 40 . Foetal movements were decreased during pregnancy. Caesarean section was necessary because of premature rupture of the membranes. Birth weight was $2450 \mathrm{~g}$. After delivery the patient showed severe muscular hypotonia, weak cry, sleepiness, poor deep tendon reflexes and abnormalities in thermoregulation. Feeding problems were noted due to a poor sucking reflex and the baby required gavage. She was discharged with diagnosis of congenital benign hypotonia. She had a psychomotor delay, non-specific mild dysmorphisms and strabismus. Karyotype was normal (46, XX). Neonatal screening for $\mathrm{CH}$ showed normal thyroxine (T4) levels and a slightly elevated TSH $(24 \mu \mathrm{U} / \mathrm{ml})$, both of which were confirmed with a blood sample. Nevertheless, she was not treated. The patient was firstly admitted at our hospital at 9 months of age because of elevated serum level of TSH $(40 \mu \mathrm{U} / \mathrm{ml}-\mathrm{nv}<4$ $\mu \mathrm{U} / \mathrm{ml})$, with normal FT4 $(8 \mathrm{pg} / \mathrm{ml}$ - n.v. 5-12.5 pg/ml). She had a supine length of $66 \mathrm{~cm}(<10$ th percentile), a body weight of $8 \mathrm{~kg}(<25 \mathrm{th}$ percentile) and a head circumference of $45.5 \mathrm{~cm}$ (97th percentile). The thyroid ultrasound revealed the absence of the gland in the neck (Fig. 1), while the $99 \mathrm{mTc}$-pertechnetate thyroid scintigraphy showed a small, ectopic, sublingual thyroid gland (Fig. 2).

Thus, levo-thyroxine therapy was promptly initiated $(8 \mu \mathrm{g} / \mathrm{kg} / \mathrm{die})$ and the dose was gradually adjusted over several months with normalization of FT4 and TSH levels.

Due to the persistence of hypotonia and poor response to stimuli, associated with the absence of sucking reflex in the first weeks of life, a brain computed tomography scan was done at 12 months of age, which showed ventricular enlargement and craniosynostosis.

Two years later, at the age of three, the patient showed poor physical and developmental progress, despite being biochemically euthyroid on levo-thyroxine substitution therapy, and associated hyperphagia, weight gain, short stature and decreased growth velocity. In addition, physical examination revealed a more distinctive phenotype, characterized by peculiar facial features (narrow bifrontal diameter, dolichocephaly, almond-shaped eyes, downturned angles of the mouth) with abundant thick saliva, small hands and feet. At this age a severe scoliosis was diagnosed, treated initially with a corset. The patient later required surgery at the age of 13 .

To evaluate growth retardation, two growth hormone (GH) stimulation tests (clonidine $0.150 \mathrm{mg} / \mathrm{m}^{2}$ orally and insulin tolerance test $0.1 \mathrm{UI} / \mathrm{kg}$ i.v. bolus) were performed and both of them were consistent with a diagnosis of GH deficiency [GH peak $1.7 \mathrm{ng} / \mathrm{ml}$ and $5.6 \mathrm{ng} / \mathrm{ml}$, respectively $(\mathrm{nv}>10 \mathrm{ng} / \mathrm{ml})]$. The combined test [GHRH $(1 \mu \mathrm{g} / \mathrm{kg})+$ Arginine $(0,5 \mathrm{~g} / \mathrm{kg}$ iv $)]$ confirmed the presence of reduced GH response [GH peak $8.7 \mathrm{ng} / \mathrm{ml}$ (nv $>20 \mathrm{ng} / \mathrm{ml}$ )]. Pituitary MRI revealed an empty sella with a small, hypoplastic pituitary gland at its base.

Therefore, GH therapy was initiated at $0.24 \mathrm{mg} / \mathrm{kg} /$ week, subsequently dose adjusted based on IGF-1 levels

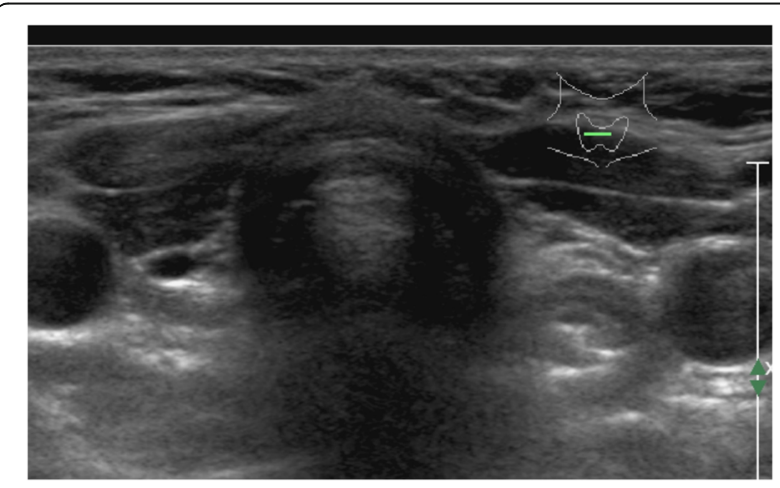

Fig. 1 Ultrasonography of the neck showed absence of thyroid tissue 


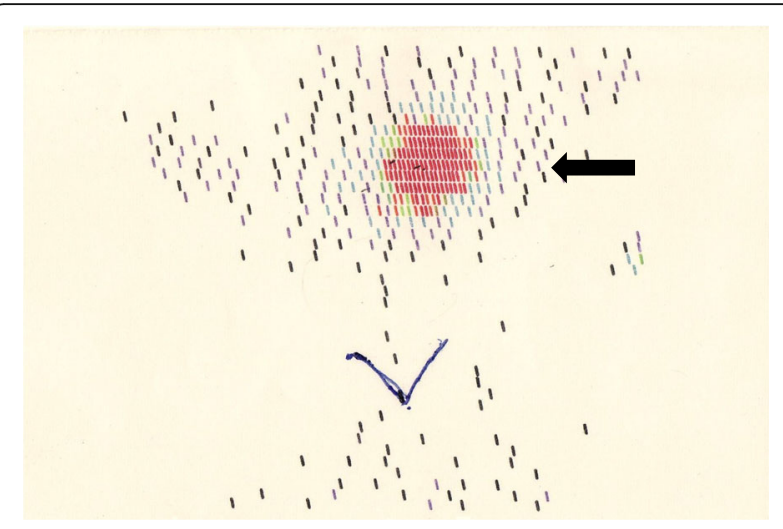

Fig. 2 99mTc-pertechnetate thyroid scintigraphy showed a small, ectopic, sublingual thyroid gland (black arrow)

and growth curve, and continued until the age of 12.9 years.

At the age of 9, given her constellation of signs and symptoms, PWS diagnosis was considered, as a possible cause of her clinical picture, but because of the mother's initial refusal genetic tests were performed only at the age of 16. Methylation analysis and DNA polymorphism analysis of chromosome 15 confirmed the presence of UPD15.

Since the age of 10.2 both central and obstructive sleep apnea were noted on polysomnographic study, for which the child subsequently required non-invasive ventilation (NIV).

She also presented skin-picking starting at age 11 and worsening with age.

At the age of 14.1 a right ovarian cyst was removed. Since our patient had no spontaneous menarche, she underwent a LHRH test at age 22 that documented a complete hypogonadism of central origin with concomitant low estradiol levels. Consequently, sex steroid replacement was initiated.

Corticotrophin deficiency was excluded because cortisol response to low-dose ACTH test was normal $(22 \mu \mathrm{g} / \mathrm{dL}-\mathrm{nv}>18.1 \mu \mathrm{g} / \mathrm{dL})$.

Starting from transition phase, she had episodes of psychosis that required antipsychotic therapy. Over the years a progressive worsening of obesity was observed, due to her uncontrolled eating habits and poor compliance with diet therapy. At the age of 24 a bioenteric intragastric balloon (BIB) was inserted for treatment of morbid obesity, with a transient weight loss of $13 \mathrm{~kg}$ in 9 months.

At the last examination (28.9 years), the patient's anthropometric data were the following: height $142.8 \mathrm{~cm}$ (-3.07 SDS); weight $119.2 \mathrm{~kg}$, body mass index (BMI) $59 \mathrm{~kg} / \mathrm{m}^{2}$. Blood pressure was normal. She presented mild mental retardation, outcomes of operated scoliosis and skin-picking, and continued utilization of NIV for sleep disordered breathing. Oral glucose tolerance test was normal, but hyperinsulinism was present. She is on therapy with L-thyroxine $(125 \mu \mathrm{g} / \mathrm{die})$, sex steroids replacement and psychotropic drugs (risperidone and carbamazepine) for recurrent psychotic crises.

\section{Discussion}

Up until the last decade the thyroid axis of PWS subjects was generally considered to be normal or slightly altered, with a similar frequency of hypothyroidism in comparison to the general population [15-17]. More recently, other studies reported a higher prevalence of hypothyroidism in PWS, mostly due to a central defect of central origin (hypothalamic hypothyroidism) $[8,9,12,18-20]$.

At present, data on the incidence of other thyroid alterations, including primary hypothyroidism, are inconsistent in these patients. In this light, the most interesting finding in our PWS patient is her concurrent $\mathrm{CH}$, due to a sublingual ectopic thyroid gland. To our knowledge, this is the second reported occurrence of ectopic thyroid tissue in PWS [14]. In our case, high levels of TSH with normal T4 (subclinical hypothyroidism) was detected during the neonatal screening for $\mathrm{CH}$, but were not considered by the neonatologist (the child was born in a small provincial hospital) and levo-thyroxine therapy was started only at the age of 9 months. In this regard, our clinical case reports a dramatic management error of a newborn, who was screened for $\mathrm{CH}$ but was not treated promptly. However, difficulties in the interpretation of thyroid status may be explained by only slightly elevated TSH levels, probably due to combined peripheral and central hypothyroidism, as suggested by the later findings of $\mathrm{GH}$ deficiency, central hypogonadism and empty sella on MRI.

Furthermore, our case is unique in that the diagnosis of PWS was delayed because mental retardation, hypotonia, weight excess and short stature were initially attributed to hypothyroidism.

In this regard, the majority of newborns with PWS show signs and symptoms which can simulate $\mathrm{CH}$, e.g. muscular hypotonia, lethargy and poor sucking often resulting in failure to thrive. Consequently, pediatricians should be aware that patients who are found to have $\mathrm{CH}$ and severe infantile hypotonia and do not improve with adequate thyroid replacement therapy need to be further investigated for an additional diagnosis, including genetic evaluation for PWS, particularly when a distinctive phenotype becomes evident.

Finally, it is of note that a sublingual ectopic thyroid may induce local symptoms such as dysphagia, related to the potential growth of the thyroid tissue [21]. Careful consideration should be made about dysphagia in children with PWS, because swallowing dysfunction and choking may be a contributor to morbidity and mortality in PWS. 
Recently, oropharyngeal phase dysphagia with abnormal pharyngeal clearance have been demonstrated by videofluoroscopic swallow studies in infants with PWS [22].

\section{Conclusions}

In conclusion, this report suggests that, although rare, the association between $\mathrm{CH}$ and PWS may exist. Because of overlapping symptoms and signs the presence of $\mathrm{CH}$ may delay diagnosis of PWS. In this light, PWS should always be considered in patients with $\mathrm{CH}$ and failure to thrive who do not improve adequately with levo-thyroxine therapy.

As a consequence, current clinical management of both pathological conditions should be revised in order to avoid diagnostic delay. In this light, it might be advisable to regularly assess thyroid function in all PWS children, even if neonatal screening for $\mathrm{CH}$ is negative.

\section{Abbreviations}

PWS: Prader-Willi syndrome; CH: Congenital hypothyroidism;

UPD15: Maternal uniparental disomy for chromosome 15; ID: Imprinting center defects; GH: Growth hormone; TSH: Thyroid-stimulating hormone; FT4: Free thyroxine; TRH: Thyrotropin-releasing hormone; NIV: Non-invasive ventilation

\section{Acknowledgements}

We would like to thank the patient and her family for their collaboration. We are also grateful to Dr. Mary Lombardi Heywood, who kindly revised the English text.

\section{Funding}

None.

\section{Availability of data and materials}

All data are contained within the article.

\section{Authors' contributions}

$S B, D F$ and $A C$ interpreted the data and drafted the manuscript. GG revised the manuscript. SB, DF, AC and AC participated in the endocrinological treatment, and collected the data. All the authors read and approved the final manuscript.

\section{Ethics approval and consent to participate}

The study has been approved by the authors' institutional Ethical Research Committee. Both the patient and her legal guardian have given their written informed consent to participate.

\section{Consent for publication}

Written informed consent was obtained from the patient and her parent for publication of this case report and any accompanying images. A copy of the written consent is available for review by the Editor-in-Chief of this journal.

\section{Competing interests}

The authors declare that they have no competing interests in the manuscript.

\section{Publisher's Note}

Springer Nature remains neutral with regard to jurisdictional claims in published maps and institutional affiliations.

\section{Author details}

'Autoimmune Endocrine Diseases Unit, Bambino Gesù Children's Hospital, Research Institute, Palidoro, Rome, Italy. ${ }^{2}$ Endocrinology and Diabetology Unit, Bambino Gesù Children's Hospital, Research Institute, Palidoro, Rome, Italy. ${ }^{3}$ Division of Auxology, Italian Auxological Institute, Research Institute, Verbania, Piancavallo, Italy.
Received: 30 June 2017 Accepted: 11 September 2017

Published online: 22 September 2017

\section{References}

1. Butler MG, Manzardo AM, Forster JL. Prader-Willi Syndrome. Clinical Genetics and Diagnostic Aspects with Treatment Approaches. Curr Pediatr Rev. 2016; 12:136-66.

2. Lionti T, Reid SM, White SM, Rowell MM. A population-based profile of 160 Australians with Prader-Willi syndrome: trends in diagnosis, birth prevalence and birth characteristics. Am J Med Genet A. 2015;167A:371-8.

3. Angulo MA, Butler MG, Cataletto ME. Prader-Willi syndrome: a review of clinical, genetic, and endocrine findings. J Endocrinol Investig. 2015;38: 1249-63.

4. Cassidy SB, Schwartz S, Miller JL, Driscoll DJ. Prader-Willi syndrome. Genet Med. 2012;14:10-26.

5. Burman $P$, Ritzen EM, Lindgren AC. Endocrine dysfunction in Prader-Willi syndrome: a review with special reference to GH. Endocr Rev. 2001;22:787-99.

6. Emerick JE, Vogt KS. Endocrine manifestations and management of PraderWilli syndrome. Int J Pediatr Endocrinol. 2013;1:14.

7. Sharkia M, Michaud S, Berthier MT, Giguère Y, Stewart L, Deladoëy J, Deal C, Van Vliet G, Chanoine JP. Thyroid function from birth to adolescence in Prader-Willi syndrome. J Pediatr. 2013:163:800-5.

8. Bacheré N, Diene G, Delagnes V, Molinas C, Moulin P, Tauber M. Early diagnosis and multidisciplinary care reduce the hospitalization time and duration of tube feeding and prevent early obesity in PWS infants. Horm Res. 2008:69(1):45-52.

9. Vaiani E, Herzovich V, Chaler E, Chertkoff L, Rivarola MA, Torrado M, Belgorosky A. Thyroid axis dysfunction in patients with Prader-Willi syndrome during the first 2 years of life. Clin Endocrinol. 2010;73(4):546-50.

10. Dimitropoulos A, Molinari L, Etter K, Torresani T, Lang-Muritano M, Jenni OG, Largo RH, Latal B. Children with congenital hypothyroidism: long-term intellectual outcome after early high-dose treatment. Pediatr Res. 2009;65(2):242-8.

11. Jacob $\mathrm{H}$, Peters $\mathrm{C}$. Screening, diagnosis and management of congenital hypothyroidism. European Society for Paediatric Endocrinology Consensus Guideline. Arch Dis Child Educ Pract Ed. 2015;100(5):260-3. Review

12. Miller JL, Goldstone AP, Couch JA, Shuster J, He G, Driscoll DJ, Liu Y, Schmalfuss IM. Pituitary abnormalities in Prader-Willi syndrome and early onset morbid obesity. Am J Med Genet A. 2008;146A:570-7.

13. Insoft RM, Hurvitz J, Estrella E, Krishnamoorthy KS. Prader-Willi syndrome associated with fetal goiter: a case report. Am J Perinatol. 1999;16:29-31.

14. Sher C, Bistritzer T, Reisler G, Reish O. Congenital hypothyroidism with Prader-Willi syndrome. J Pediatr Endocrinol Metab. 2002;15:105-7.

15. Bray GA, Dahms WT, Swerdloff RS, Fiser RH, Atkinson RL, Carrel RE. The Prader-Willi syndrome: a study of 40 patients and a review of the literature. Medicine (Baltimore). 1983;62(2):59-80. Review

16. Butler MG, Theodoro M, Skouse JD. Thyroid function studies in Prader-Willi syndrome. Am J Med Genet A. 2007;143:488-92.

17. Festen DA, Vissert TJ, Otten JB, Wit JM, Duivenvoorden HJ, Hokken-Koelega ACS. Thyroid hormone levels in children with Prader-Willi syndrome before and during growth hormone treatment. Clin Endocrinol. 2007;67:449-56.

18. Tauber M, Barbeau C, Jouret B, Pienkowski C, Malzac P, Moncla A, Rochiccioli P. Auxological and endocrine evolution of 28 children with Prader-Willi syndrome: effect of GH therapy in 14 children. Horm Res. 2000; 53(6):279-87.

19. Diene G, Mimoun E, Feigerlova E, Caula S, Molinas C, Grandjean H, Tauber M. French Reference Centre for PWS. Endocrine disorders in children with Prader-Willi syndrome-data from 142 children of the French database. Horm Res Paediatr. 2010;74:121-8.

20. van Nieuwpoort IC, Sinnema M, Castelijns JA, Twisk JW, Curfs LM, Drent ML. The GH/IGF-I axis and pituitary function and size in adults with Prader-Willi syndrome. Horm Res Paediatr. 2011:75:403-11.

21. Adelchi C, Mara P, Melissa L, De Stefano A, Cesare M. Ectopic thyroid tissue in the head and neck: a case series. BMC Res Notes. 2014;7:790.

22. Salehi P, Chen M, Beck A, McAfee A, Kim S-J, Herzig L, Leavitt A. Abnormal Videofluoroscopic Swallow Studies (VFSS) in infants with Prader-Willi syndrome indicate a high rate of silent aspiration. Horm Res Paediatr. 2016; 86(Suppl 1):88-9. (abstract) 